\title{
Ground Test Strategy for a Nuclear Thermal Propulsion Engine
}

\author{
David Coote \\ NASA/Stennis Space Center \\ Propulsion and Energy Forum, 9-11 July 2018 \\ Duke Energy Convention Center, Cincinnati, Ohio
}




\section{Introduction}

- Nuclear Thermal Propulsion (NTP) is directly relevant to the Agency's vision, mission, and long-term goal of expanding human presence into the solar system and to the surface of Mars

- Provides the fastest trip time of all currently obtainable advanced propulsion systems.

- Offers high energy density and a specific impulse roughly double that of the highest performing traditional chemical systems.

- NTP project is funded through the Space Technology Mission Directorate's (STMD) Game Changing Development (GCD) program

- Goal is to determine the feasibility and affordability of a Low Enriched Uranium (LEU)-based NTP engine with credible cost and schedule confidence. 


\section{Introduction}

- An NTP engine has substantial commonality with conventional liquid rocket engines.

- Primary difference is replacing combustion of propellants with heating of a single propellant via a nuclear reactor.

- Exhaust may contain radioactive particles and noble gases due to a reactor anomaly or failure.

- NASA has developed the Rocket Exhaust Capture System (RECS) concept to capture and isolate NTP engine exhaust from the environment to mitigate the related environmental

- Driving Requirements

- Thrust: $25 \mathrm{k} \mathrm{lbf}$

- Burn time: $50 \mathrm{~min}+10 \%$ margin = $55 \mathrm{~min}$ burn

- Exhaust temp: $2850 \mathrm{~K}$

- Hydrogen flow rate: $28 \mathrm{lbm} / \mathrm{s}$

- Max allowable back pressure: 25 psia

- Meet regulatory requirements for dose rates

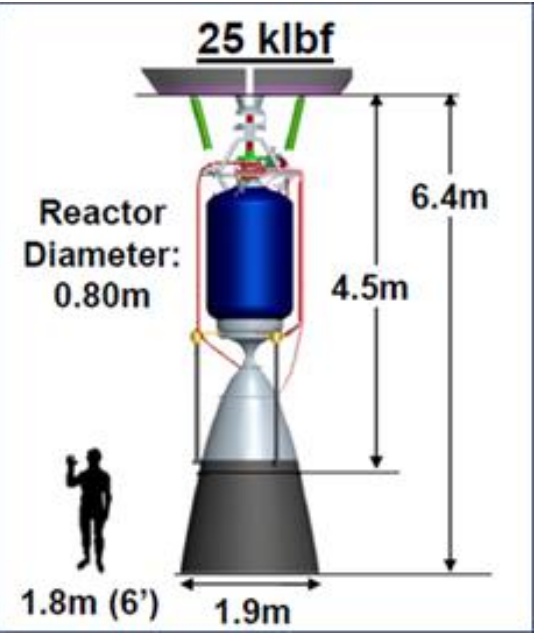

Preliminary Engine Architecture 



\section{Rocket Exhaust.Capture System}

\section{Preliminary System Sizing - 25 klbf Engine}

\section{SPACE TECH'S GAME CHANGING DEVELOPMENT PROGRAM}

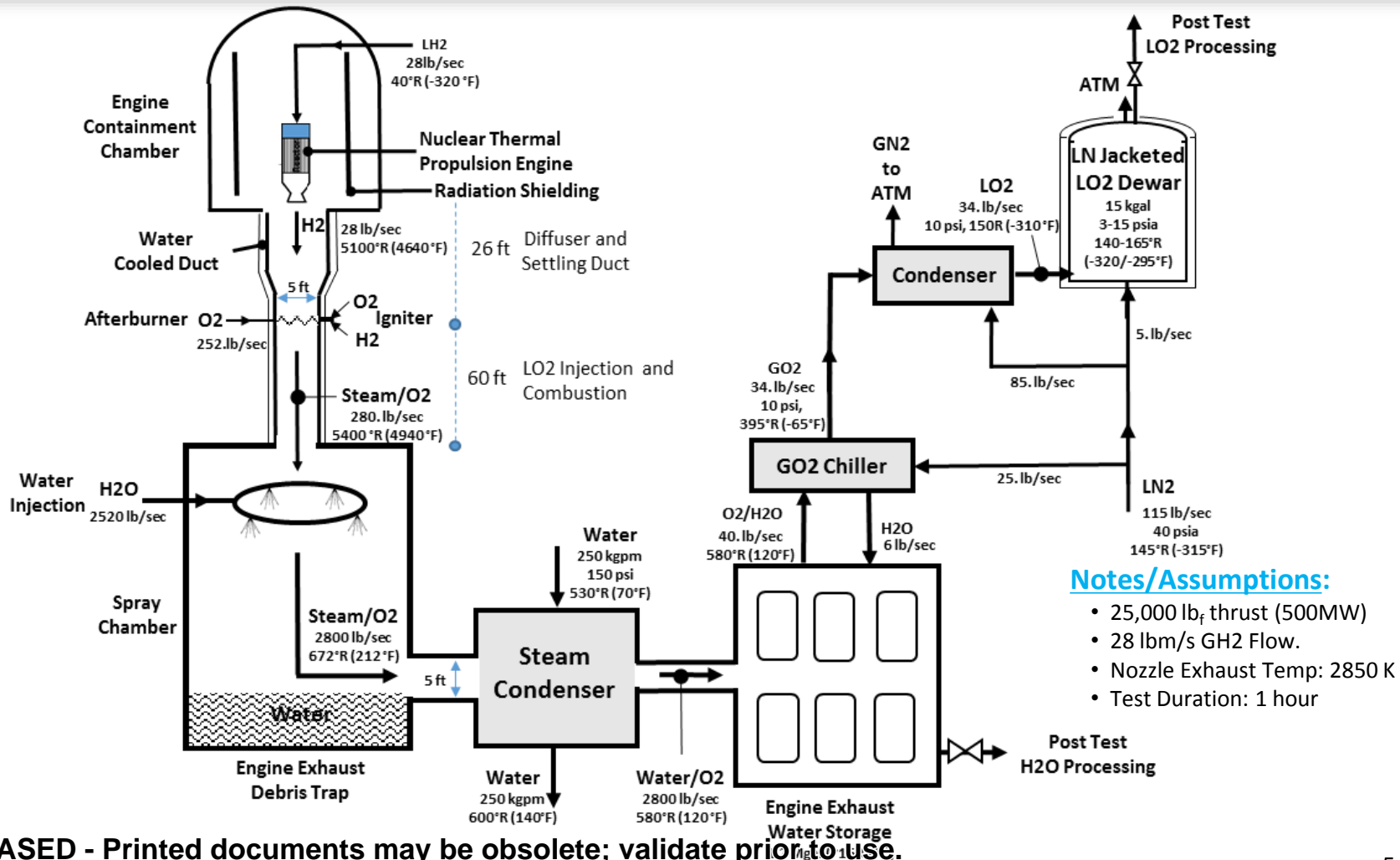

RELEASED - Printed documents may be obsolete; validate priorntertorise. 


\section{Rocket Exhaust Capture System Is Expected to Be Built at NASA's Stennis Space Center (SSC)}

- SSC's A3 test facility and its supporting propulsion test infrastructure is uniquely suited to accommodate NTP engine system development and specifically, the RECS implementation requirements.

- Most of the RECS major structural elements are readily available.

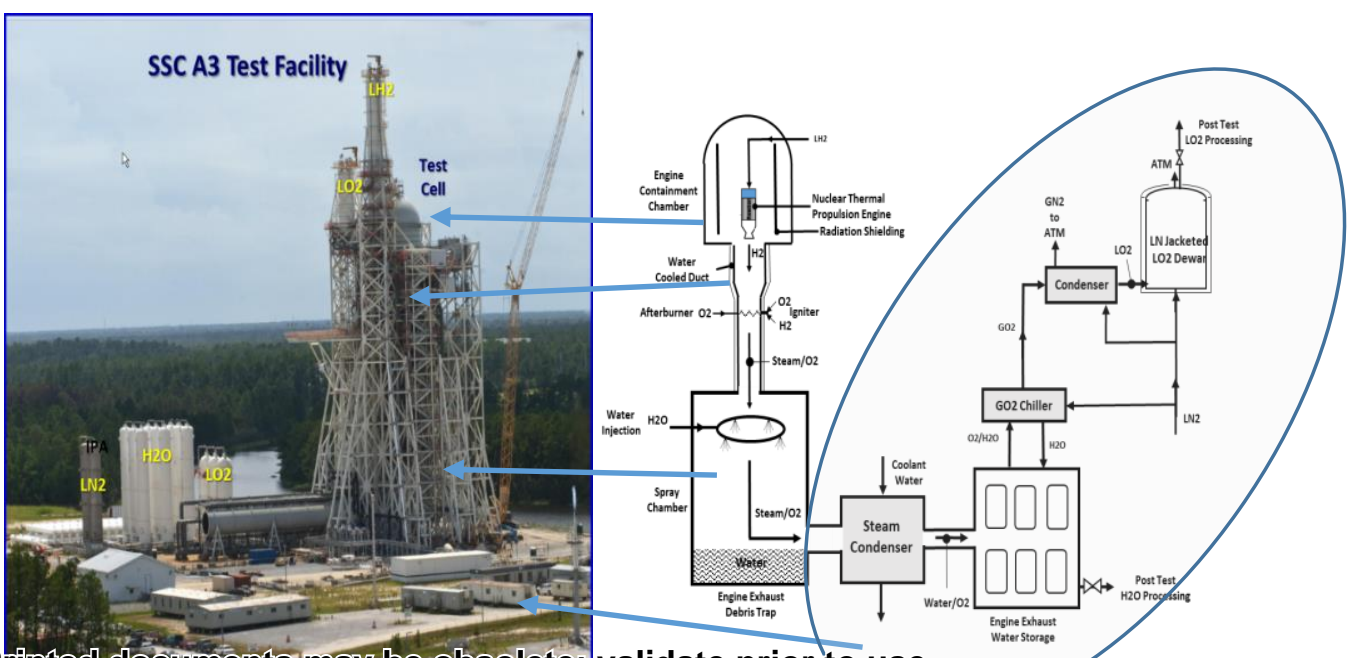

Printed documents-may=be-obsolete; validate prior to use. 


\section{(9) Rocket Exhaust Capture System Subscale Test Project}

- Phase 1 Objective: Demonstrate the basic performance of the RECS to capture, contain, process, and store rocket exhaust effluents

- Utilizes an existing, well-characterized DTF Thruster ( $250 \mathrm{lbf})$ to simplify $\mathrm{H} 2$ afterburning

- Phase 2 Objectives: Demonstrate

- Stable H2 combustion flame holding following LO2 injection

- Back pressure control in the settling and combustion duct sections during NTP engine simulated transient start and shutdown $\mathrm{H} 2$ flow conditions

- Simulation of NTP engine start and shutdown transient flow conditions using a Hydrogen Wave Heater

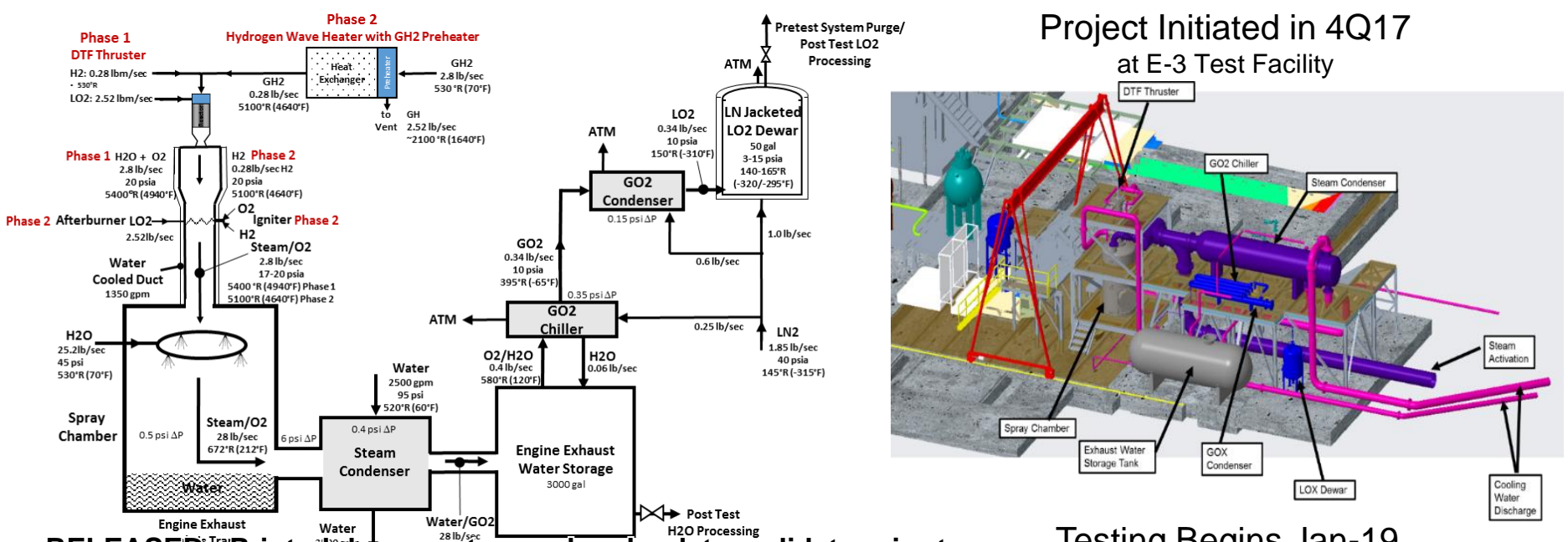

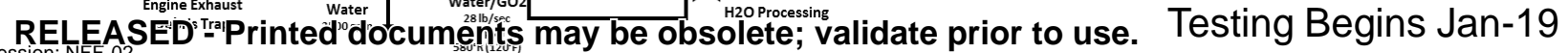




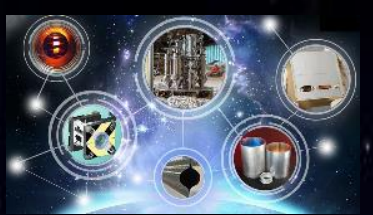

\section{Rocket Exhaust Capture System Subscale Test Project

Phase 2

Phase 1 DTF Thruster

$\mathrm{H} 2: 0.28 \mathrm{lbm} / \mathrm{sec}$ - $530^{\circ} \mathrm{R}$ LO2: $2.52 \mathrm{lbm} / \mathrm{se}$

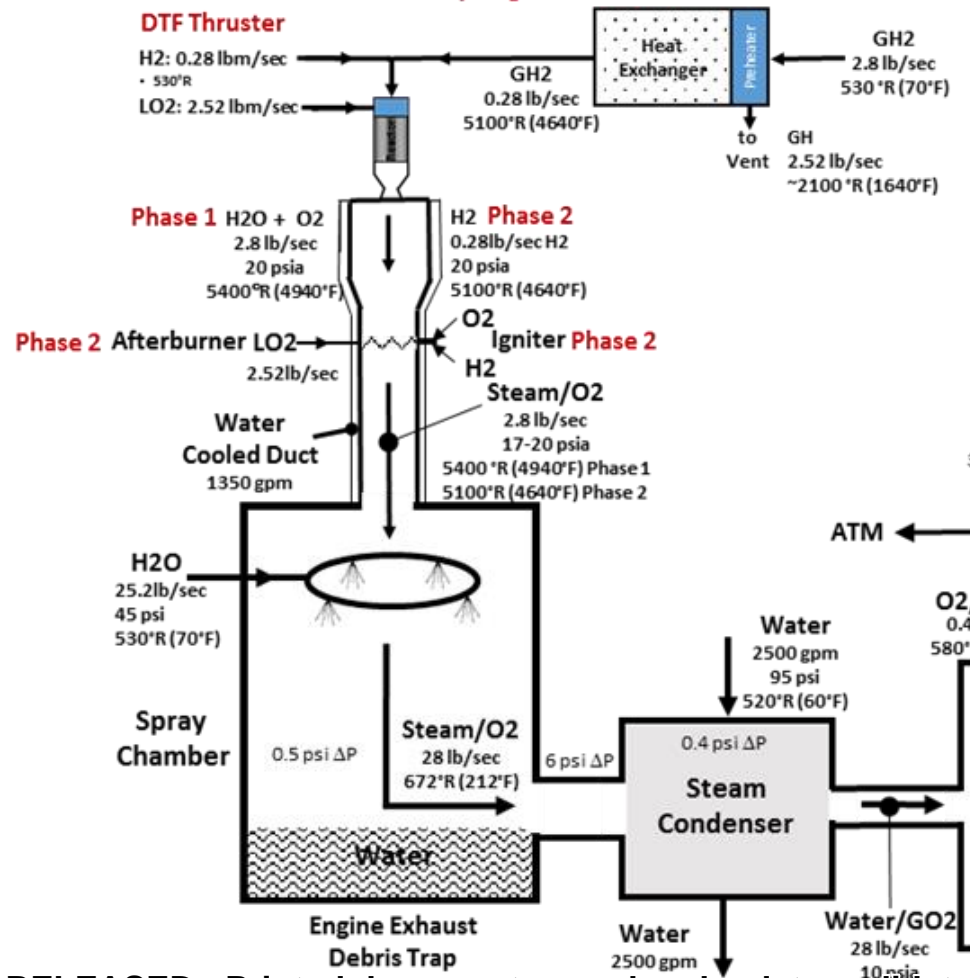

Hydrogen Wave Heater with GH2 Preheater

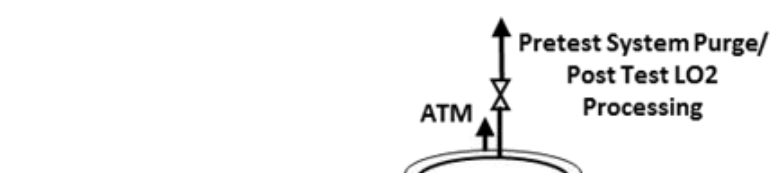

RELEASED - Printed documents may be obsolete; 5 valifidate prior to use.

Engine Exhaust

Water Storage $3000 \mathrm{gal}$

LN Jacketed

LO2 Dewar

$0.34 \mathrm{lb} / \mathrm{sec}$

10 psia

50 gal

3-15 psia

140-165'R

$\left(-320 /-295^{\circ} \mathrm{F}\right)$

GO2

GO2

$0.34 \mathrm{lb} / \mathrm{sec}$
$10 \mathrm{psia}$

$395^{\circ} \mathrm{R}\left(-65^{\circ} \mathrm{F}\right)$

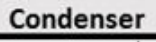

$0.15 p s i \Delta p$

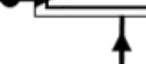

$1.0 \mathrm{lb} / \mathrm{sec}$

$0.6 \mathrm{lb} / \mathrm{sec}$

GO2

Chiller

$0.25 \mathrm{lb} / \mathrm{sec}$

LN2

$85 \mathrm{lb} / \mathrm{sec}$

40 psia

$145^{\circ} \mathrm{R}\left(-315^{\circ} \mathrm{F}\right)$

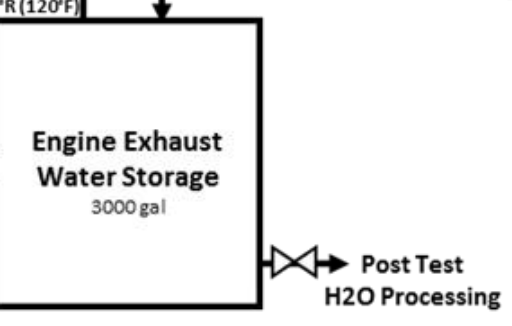




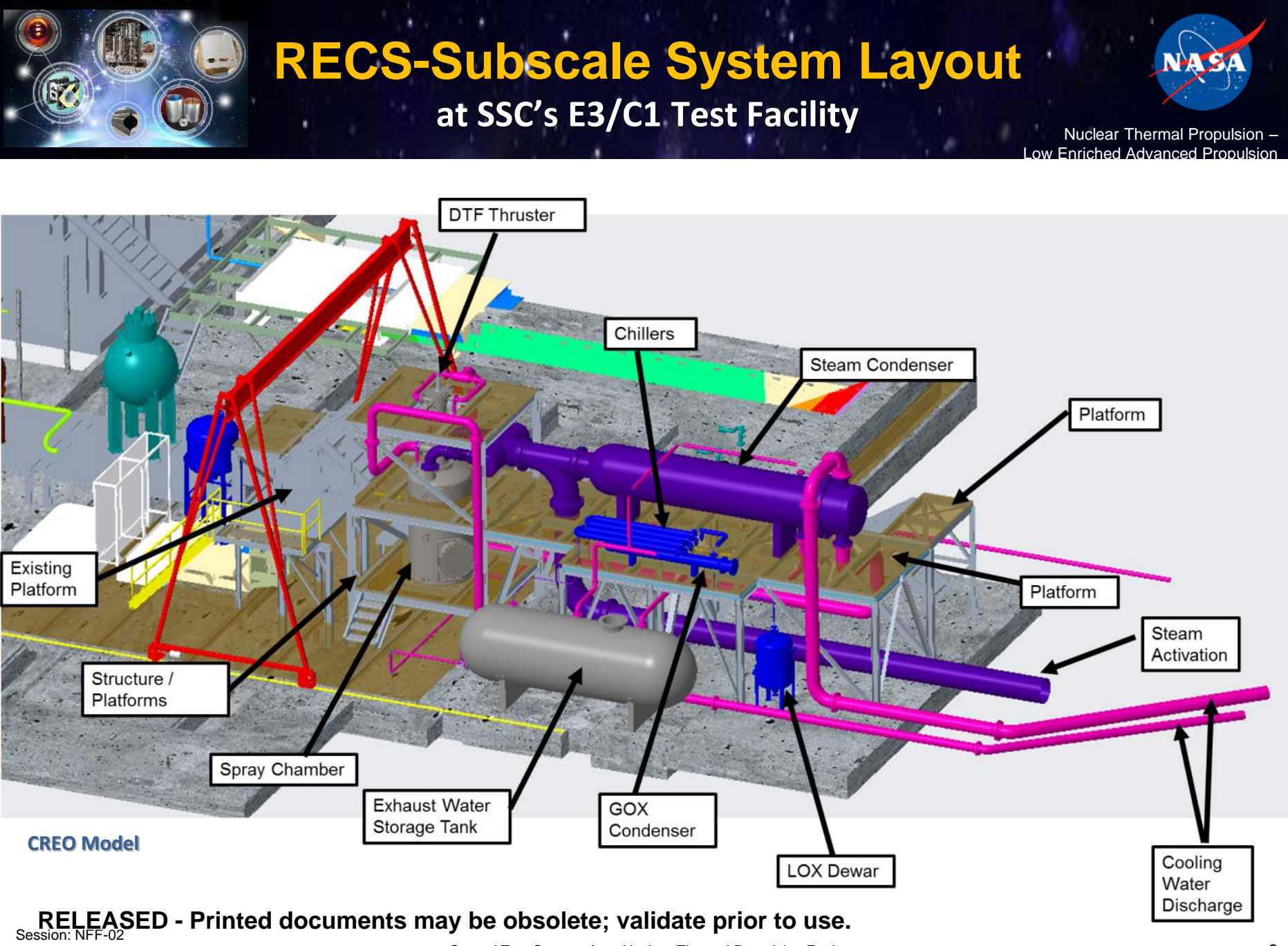




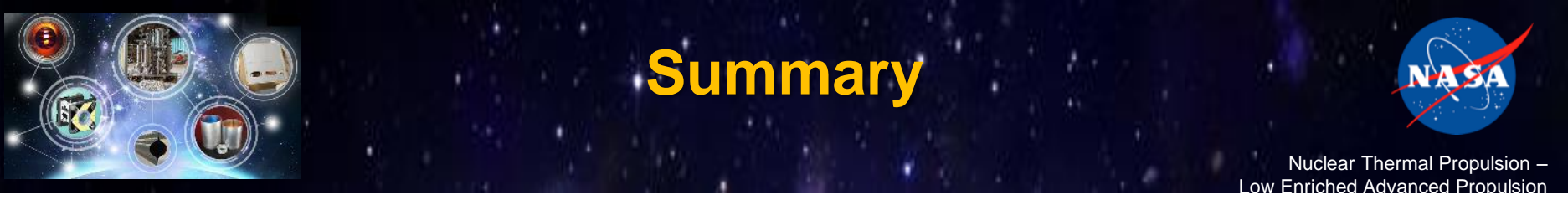

- NTP is directly relevant to the Agency's vision, mission, and long-term goal of expanding human presence into the solar system and to the surface of Mars

- The RECS concept captures and isolates NTP engine exhaust from the environment to mitigate the potential environmental risks.

- SSC has substantial existing infrastructure to support RECS testing.

- A Subscale RECS test project is in work at SSC

- Will demonstrate the basic performance of the RECS to capture, contain, process, and store rocket exhaust effluents

- It is a critical element of the NTP project

- Will support site licensing, proof-of-concept validation, and engineering insight to the full scale system. 